\title{
Vitamin D3 augments the antidepressant effect of agomelatine against repeated corticosterone-induced depressive-like behavior in rats
}

\author{
Hanan Tawfeek Emam*, Nashwa Hassan Abu-Raia
}

Department of Clinical Pharmacology, Faculty of Medicine, Benha University, Egypt

\author{
Received: 18 November 2020 \\ Revised: 08 December 2020 \\ Accepted: 11 December 2020

\section{*Correspondence:} \\ Dr. Hanan Tawfeek Emam, \\ Email: hanantawfeek@yahoo.com
}

Copyright: ( $)$ the author(s), publisher and licensee Medip Academy. This is an open-access article distributed under the terms of the Creative Commons Attribution Non-Commercial License, which permits unrestricted non-commercial use, distribution, and reproduction in any medium, provided the original work is properly cited.

\begin{abstract}
Background: Depression is a highly complex psychiatric disorder that remains a major burden on society. The present study was aimed to detect the neuroprotective effect of agomelatine or/and vitamin D3 on the progression of depression induced by chronic administration of corticosterone.

Methods: Rats were classified into 4 equal groups; corticosterone-untreated group, agomelatine-treated group, vitamin D3-treated group, and (agomelatine and vitamin D3)-treated group.

Results: Agomelatine or/and vitamin D3 caused significant improvement of behavioral parameters of depression, increase in serotonin, dopamine, and brain-derived neurotrophic factor (BDNF) with a significant decrease in tumor necrosis factor (TNF)-alpha and caspase-3 levels of brain tissue with a more significant effect of combination therapy over the effect of each drug alone.

Conclusions: Vitamin D3 augments the antidepressant effect of agomelatine against depressive-like behavior in rats.
\end{abstract}

Keywords: Depression, Agomelatine, Vitamin D3, Apoptosis, BDNF

\section{INTRODUCTION}

Depression is the most frequently life-threatening neuropsychiatric disorder with a lifetime prevalence of about $15-25 \%$. Worldwide, it ranks the fourth leading cause of disability. ${ }^{1}$ Moreover, according to the World Health Organization, it will be the second major contributor to the worldwide burden of disease by the year $2030 .^{2}$

The brain contains enormous numbers of serotonergic and dopaminergic neurons. Serotonin (5-hydroxytryptamine: 5HT) is the major neurotransmitter system in the brain. Changes in cerebral 5HT levels have been linked to alterations in behavioral functions that are observed in depression. And a variety of postmortem studies have reported low 5HT levels in the brains of depressed patients compared to non-depressed patients. ${ }^{3}$ In the same way, dopamine (DA) level alterations have been linked to impaired cognitive performance which is associated with depression. ${ }^{4}$

Agomelatine is a melatonin MT1/MT2 receptor agonist and a serotonin receptor antagonist, it acts synergistically in serotonergic and melatonergic systems, apparently has a distinct mechanism of action from the other antidepressant drugs, its psychotropic effects are mainly caused by the synergy between the melatonergic and 5HT2C receptor properties of the compound. ${ }^{5}$ However, agomelatine only has modest efficacy with response rates reported at approximately $50 \% .^{6}$

The active vitamin $\mathrm{D}$ mediates its biological effects by binding to the vitamin $\mathrm{D}$ receptors (VDR), which are expressed, all over the brain, including areas involved in memory such as the hippocampus and dentate gyrus. ${ }^{7}$ 
Likewise, the enzyme that synthesizes the active form of vitamin $\mathrm{D}, 1 \alpha$-hydroxylase is produced in several cerebral regions. ${ }^{8}$

Vitamin D3 is able to increase dopamine synthesis itself via increasing its synthetic enzyme tyrosine hydroxylase. ${ }^{9}$ Also, it decreases the production of proinflammatory cytokines in a variety of cell types including monocytes, microglia, an important source of proinflammatory cytokines in the brain. ${ }^{10}$ and upregulates neurotrophin factors, such as BDNF. ${ }^{11}$ However, recommendations for the use of vitamin D supplementation in depression are not yet justified.

So, this study was designed to detect the possible neuroprotective effect of agomelatine and vitamin $\mathrm{D}_{3}$ and their combination on the progression of depression in a rat model of depressive-like behavior induced by chronic administration of corticosterone and to assess the possible underlying mechanisms.

\section{METHODS}

\section{Animals}

Adult male albino Wistar rats weighing $150-180 \mathrm{gm}$ at the beginning of the study were used. They have acclimatized for one week in groups (5/cage) in a fully ventilated room at a room temperature of $25{ }^{\circ} \mathrm{C}$. Rats were allowed to ad libitum, access to water, and a balanced diet in the pharmacology department, Benha faculty of medicine. The study period extended from Feb to May-2019. All experimental protocols were approved by the research ethics committee at the faculty of medicine, Benha university.

\section{Experimental design}

At the beginning of the experiment rats were divided into 5 groups.

Group (I): control group contained 20 rats divided into four subgroups each 5 rats. Ia (negative): left without any therapy. Ib (solvent): only receive saline orally and intraperitoneally in volumes comparable to that of tested drugs. Ic (Vitamin D3): given vitamin D3 (12 mg/kg orally) once daily for 3 weeks. Id (Agomelatine): given agomelatine at a dose of $(40 \mathrm{mg} / \mathrm{kg}$, PO.) once daily for 3 weeks.

Group (II): Untreated depression-like behavior group formed of 10 rats: The rats of this group were given corticosterone intraperitoneal in a dose of $40 \mathrm{mg} / \mathrm{kg}$ for 3 weeks. $^{12}$

Group (III): Agomelatine-treated depression-like behavior group. The rats of this group were given agomelatine (from sigma chemical Co., St. Louis, USA) at a dose of (40 $\mathrm{mg} / \mathrm{kg}$, orally) once daily immediately after corticosterone injection (from sigma chemical Co., St. Louis, USA) for 3weeks. ${ }^{13}$
Group (IV): Vitamin $\mathrm{D}_{3}$-treated depression-like behavior group the rats of this group were given vitamin $\mathrm{D}_{3}$ (Calbiochem, CA, USA) at a dose of $12 \mathrm{mg} / \mathrm{kg}$ orally once daily immediately after corticosterone injection for 3 weeks. $^{14}$

Group (V): Agomelatine and vitamin $\mathrm{D}_{3}$-treated depression-like behavior group the rats of this group were treated with agomelatine and vitamin $\mathrm{D}_{3}$ as described above.

\section{Parameters measured}

\section{Assessment of behavior changes}

The behavior changes were assessed at the last day of treatment by using the following:

\section{Open field test}

The open field apparatus was constructed of black wood and measured $72 \times 72 \mathrm{~cm}$ with $36 \mathrm{~cm}$ walls. One of the walls was clear Plexiglas. White lines were drawn on the floor with a marker and were visible through the clear Plexiglas floor. The lines divided the floor into sixteen (16) squares each one $18 \times 18 \mathrm{~cm}$. A central square $(18 \times 18$ $\mathrm{cm}$ ) was drawn in the middle of the open field. The central square has sufficient space surrounding it to give meaning to central location as being distinct from outer locations. ${ }^{15}$

The behaviors scored by open field test include: ${ }^{16,17}$

Latency: Latency is the time taken by the animals to make its first movement in the open field apparatus. If the hippocampus was affected the anxiety level of the animal will be more, and so the animal will take more time to make its first movement. So, we can analyze the neuroprotective effect of the drug by watching the latency of the animals in the open field test.

Frequency of central square crossing: The numbers of central square entries are measures of exploratory behavior and anxiety. A high frequency of these behaviors indicates high exploratory behavior and low anxiety levels. That indirectly shows the protection of the hippocampus by the given drug.

Number of line crossing: Line Crossing is a measure that the rat crossed one of the grid lines with all four paws. The sum of line crossed measures the level of exploration and anxiety. A high frequency of these parameters indicates increased exploration and lower level of anxiety. That indirectly says the level of hippocampal protection.

Rearing: The parameter rearing explains the frequency with which the rats stood on their hind legs in the field. Rears are measures of exploration and anxiety. A high frequency of this parameter indicates increased exploration and lower level of anxiety. 


\section{Tail suspension test}

It was made by the tail-suspension box ( 55 height $\times 15$ width $\times 11.5 \mathrm{~cm}$ depth) involves suspending rats above the ground by their tails. The rat is suspended in the middle of this compartment. The approximate distance between the mouse's nose and the apparatus floor is $20-25 \mathrm{~cm} .{ }^{18}$ Rats were considered immobile only when they hung passively and completely motionless. The immobility time induced by tail suspension was recorded during a 6-min period.

\section{Biochemical measurements}

Next day after the last behavioral test, all rats were decapitated and the brains were rapidly removed and rinsed with ice-cold phosphate buffered saline (PBS) solution, pH 7.4 to remove any red blood cells and clots. Then, the brain tissues were divided into three parts: One part was weight then homogenized in $1 \mathrm{ml}$ of the homogenization buffer $(30 \mathrm{mM}$ Tris- $\mathrm{HCl}, 150 \mathrm{mM} \mathrm{NaCl}$, $1 \mathrm{mM}$ EDTA, and $1 \%$ triton X-100 supplemented with protease inhibitor cocktail). The homogenates were centrifuged at $3000 \mathrm{rpm}$ for $20 \mathrm{~min}$. The supernatants were collected and stored at $-80^{\circ} \mathrm{C}$ and used for measurement of serotonin' dopamine and TNF- $\alpha{ }^{19-22}$ The second part was used for measuring BDNF, and Caspase-3 by real-time quantitative PCR and the third part was preserved in $10 \%$ formalin for immune-histochemical examination.

\section{Real-time quantitative PCR (RT-qPCR) testing for $B D N F$, and Caspase-3}

Total RNA was isolated from $25 \mathrm{mg}$ brain tissue using total RNA purification kit (Jena bioscience Germany). It was further analyzed for quantity and quality with a dual beam spectrophotometer (Beckman Coulter, Fullerton, California, USA). For quantitative expression of BDNF, and Caspase-3 genes, the following procedure was performed; $200 \mathrm{ng}$ of the total RNA from each sample was used for cDNA synthesis by reverse transcription using High-capacity cDNA reverse transcriptase kit (applied biosystems Inc., Foster city, CA, USA). The cDNA was subsequently amplified with the SYBR green one-step PCR master Kit in a 48-well plate (applied biosystems Inc., Foster city, CA, USA) as follows: 10 minutes at $95^{\circ} \mathrm{C}$ for enzyme activation followed by 40 cycles of 15 seconds at $95^{\circ} \mathrm{C}, 20$ seconds at $55^{\circ} \mathrm{C}$, and 30 seconds at $72^{\circ} \mathrm{C}$ for the amplification step. Changes in the expression of each target gene were normalized relative to the mean critical threshold (CT) values of GAPDH housekeeping gene by the $2^{-\Delta \Delta \mathrm{CT}}$ method. ${ }^{23} 1 \mu \mathrm{L}$ of both primers specific for each target gene were used. Primer sequence specific for each gene were as follow:

-BDNF: Forward

5`AGTGATGACCATCCTTTTCCTTAC3`, Reverse 5 - CCTCAAATGTGTCATCCAAGGA -3`. -Caspase-3: Forward 5'-GTGGAACTG A CGATGATA TGGC-3'

Reverse 5'- CGCAAAGTGACTGGATGAACC-3' -GAPDH: Forward:5'-GTGGTGAAGCAGGCATCTG-3'
Reverse: 5'- AGCCGTATTCATTGTCATACCA-3'.

\section{Immuno-histochemical examination}

Brains were fixed in paraformaldehyde .and then put in paraffin according to the usual histological technique. Immunohistochemistry was used to determine the caspase3 antigen. Samples were deparaffinized and rehydrated. Caspase-3 antibodies (Thermo Fisher Scientific, USA) were stored at $4^{\circ} \mathrm{C}$ overnight. The suitable horseradish peroxidase conjugated secondary antibodies were added and the samples were kept for $60 \mathrm{~min}$. at normal room temperature. Hematoxylin Myer was used as counter stain; the sections were examined by using light microscope. Immunohistochemical procedures were performed in accordance with the manufacturer's protocols.

\section{Statistical analysis}

The collected data were tabulated and analyzed using SPSS version 16 software (SpssInc, Chicago, ILL Company). All the data are presented as mean \pm standard deviation (SD). Comparisons among groups were performed with one-way ANOVA with post hoc test (LSD) using SPSS 19.0 software. A p value below 0.05 was considered significant.

\section{RESULTS}

Examination of all subgroups of the control group showed similar results regarding biochemical examinations and immunohistochemistry; therefore, results of subgroup Ia were used to represent this group.

\section{Effect of agomelatine or/and vitamin D3 on behavior changes}

Chronic intraperitoneal injection with corticosterone caused significant increase $(\mathrm{p}<0.001)$ in latency in 5 minutes and immobility time in 6 minutes with significant decrease $(\mathrm{p}<0.001)$ in central square crossing, number of line crossing and number of rearing compared to the control group (Table 1).

Agomelatine, vitamin $\mathrm{D}_{3}$ and (agomelatine and vitamin $\mathrm{D}_{3}$ )-treated depression-like behavior groups showed significant decrease $(p<0.001)$ in latency in 5 minutes and immobility time in 6 minutes with significant increase $(\mathrm{p}<0.001)$ in central square crossing, number of line crossing and number of rearing compared to in untreated depression-like behavior group, there was significant difference $(\mathrm{p}<0.05)$ of both agomelatine and vitamin $\mathrm{D}_{3}$ treated depression-like behavior groups when used separately if compared with control group. On the other hand, there was non- significant difference $(p>0.05)$ of (agomelatine and vitamin $\mathrm{D}_{3}$ )-treated depression-like behavior group when compared to the control group (Table $1)$. 
Table 1: Latency, frequency of central square crossing, number of line crossing and number of rearing) in 5 minutes and immobility time in 6 minutes in different studied groups $(M e a n \pm S D)(n=10)$.

\begin{tabular}{|llllll|}
\hline $\begin{array}{l}\text { Groups } \\
\text { parameters }\end{array}$ & Group I & Group II & Group III & Group IV & Group V \\
\hline Latency & $2.76 \pm 0.34$ & $12.0 \pm 1.35 \mathrm{a}$ & $3.43 \pm 0.35 \mathrm{a}, \mathrm{b}$ & $5.4 \pm 0.77 \mathrm{a}, \mathrm{b}, \mathrm{c}$ & $2.82 \pm 0.68 \mathrm{~b}, \mathrm{c}, \mathrm{d}$ \\
\hline $\begin{array}{l}\text { Central square } \\
\text { crossing }\end{array}$ & $5.46 \pm 0.72$ & $0.00 \pm 0.00 \mathrm{a}$ & $2.87 \pm 0.62 \mathrm{a}, \mathrm{b}$ & $1.98 \pm 0.32 \mathrm{a}, \mathrm{b}, \mathrm{c}$ & $4.87 \pm 0.64 \mathrm{~b}, \mathrm{c}, \mathrm{d}$ \\
\hline $\begin{array}{l}\text { Number of line } \\
\text { crossing }\end{array}$ & $68.4 \pm 5.2$ & $10.2 \pm 1.38 \mathrm{a}$ & $51.8 \pm 4.32 \mathrm{a}, \mathrm{b}$ & $36.4 \pm 3.88 \mathrm{a}, \mathrm{b}, \mathrm{c}$ & $65.2 \pm 5.12 \mathrm{~b}, \mathrm{c}, \mathrm{d}$ \\
\hline $\begin{array}{l}\text { Number of } \\
\text { rearing }\end{array}$ & $26.7 \pm 2.1$ & $4.6 \pm 0.52 \mathrm{a}$ & $19.8 \pm 2.12 \mathrm{a}, \mathrm{b}$ & $10.2 \pm 1.73 \mathrm{a}, \mathrm{b}, \mathrm{c}$ & $25.6 \pm 2.12 \mathrm{~b}, \mathrm{c}, \mathrm{d}$ \\
\hline $\begin{array}{l}\text { Immobility time } \\
\text { (sec) }\end{array}$ & $73.2 \pm 6.28$ & $234.7 \pm 17.72 \mathrm{a}$ & $102.8 \pm 8.29 \mathrm{a}, \mathrm{b}$ & $135.7 \pm 12.06 \mathrm{a}, \mathrm{b}, \mathrm{c}$ & $74.2 \pm 6.28 \mathrm{~b}, \mathrm{c}, \mathrm{d}$ \\
\hline
\end{tabular}

Table 2: Serotonin, dopamine, TNF-alpha, levels in different studied groups $($ Mean \pm SD) $(n=10)$.

\begin{tabular}{|llll|}
$\begin{array}{l}\text { Parameters } \\
\text { groups }\end{array}$ & $\begin{array}{l}\text { Serotonin } \\
(\mathbf{n g} / \mathrm{g} \text { tissue })\end{array}$ & $\begin{array}{l}\text { Dopamine } \\
(\mathrm{ng} / \mathrm{g} \text { tissue) }\end{array}$ & $\begin{array}{l}\text { TNF-alpha } \\
\text { (Pg./g tissue) }\end{array}$ \\
\hline Group I & $28.6 \pm 1.9$ & $31.2 \pm 2.62$ & $4.6 \pm 0.35$ \\
\hline Group II & $6.8 \pm 0.73 \mathrm{a}$ & $3.6 \pm 0.21 \mathrm{a}$ & $20.3 \pm 1.67 \mathrm{a}$ \\
\hline Group III & $17.3 \pm 1.82 \mathrm{a}, \mathrm{b}$ & $18.9 \pm 1.78 \mathrm{a}, \mathrm{b}$ & $9.7 \pm 0.8 \mathrm{a}, \mathrm{b}$ \\
\hline Group IV & $10.2 \pm 1.03 \mathrm{a}, \mathrm{b}, \mathrm{c}$ & $12.1 \pm 1.18 \mathrm{a}, \mathrm{b}, \mathrm{c}$ & $13.7 \pm 1.30 \mathrm{a}, \mathrm{b}, \mathrm{c}$ \\
\hline Group V & $26.8 \pm 2.2 \mathrm{~b}, \mathrm{c}, \mathrm{d}$ & $29.7 \pm 2.41 \mathrm{~b}, \mathrm{c}, \mathrm{d}$ & $4.9 \pm 0.61 \mathrm{~b}, \mathrm{c}, \mathrm{d}$ \\
\hline
\end{tabular}

a $\mathrm{p}<0.05$ compared with group I (control group); $\mathrm{b} \mathrm{p}<0.05$ compared with group II (untreated depression-like behavior group); $\mathrm{p}<0.05$ compared with group III (agomelatine-treated depression-like behavior group); $\mathrm{d} p<0.05$ compared with group IV (vitamin D3-treated depression-like behavior group); group V (agomelatine and vitamin D3-treated depression-like behavior group).

Values are expressed as means $\pm \mathrm{SD}, \mathrm{n}=10$. Value $\mathrm{p}<0.05$ is significant tested by using one-way analysis of variance (ANOVA) and post hoc multiple comparisons. a $\mathrm{p}<0.05$ compared with group I (control group); b $\mathrm{p}<0.05$ compared with group II (untreated depression-like behaviour group); $\mathrm{c} p<0.05$ compared with group III (agomelatine-treated depression-like behaviour group); $\mathrm{d}$ p $<0.05$ compared with group IV (vitamin $\mathrm{D}_{3}$-treated depression-like behaviour group); group V (agomelatine and vitamin $\mathrm{D}_{3}$-treated depression-like behaviour group).

\section{Effect of agomelatine or/and vitamin D3 on serotonin, dopamine and TNF-alpha brain tissue levels in different studied groups}

Untreated depression-like behavior group showed significant decrease $(\mathrm{p}<0.001)$ in serotonin and dopamine with significant increase $(\mathrm{p}<0.001)$ in TNF-alpha brain tissue levels when compared to control group.

Agomelatine, vitamin $\mathrm{D}_{3}$ and (agomelatine and vitamin

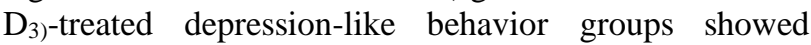
significant increase $(p<0.001)$ in serotonin and dopamine with significant decrease $(\mathrm{p}<0.001)$ in TNF-alpha of brain tissue levels when compared to untreated depression-like behavior group

There was still significant difference $(\mathrm{p}<0.001)$ of both agomelatine and vitamin $\mathrm{D}_{3}$-treated depression-like behavior groups when used separately compared to control group. On the other hand, there was non-significant difference $(\mathrm{p}>0.05)$ of (agomelatine and vitamin $\mathrm{D}_{3)^{-}}$ treated depression-like behavior group when compared with control group. (Table 2).

Effect of agomelatine or/and vitamin D3 on brain BDNF, and caspase-3 expressions in experimental groups

Chronic intraperitoneal injection of corticosterone caused significant increase $(\mathrm{p}<0.05)$ in caspase-3 and significant decrease in BDNF mRNA expressions in brain tissue. While, either agomelatine- or vitamin D3 treated depression-like behavior groups showed significant decrease $(\mathrm{p}<0.05)$ in caspase- 3 and significant increase in BDNF mRNA expressions in brain tissue compared to untreated depression-like behavior group, but still there is significant difference $(\mathrm{p}<0.05)$ if compared with control group. On the other hand, (agomelatine and vitamin D3treated group) showed non-significant difference $(p>0.05)$ when compared to the control group (Figure 1).

\section{Immunohistochemistry examination}

The control group showed minimal nuclear and cytoplasmic expression of caspase 3 antigen Figure 2 (A). While, the untreated depression-like behavior group showed marked nuclear and cytoplasmic expression of caspase 3 antigen Figure 2 (B) On the other hand, either agomelatine or vitamin D3 treated depression-like behavior groups showed moderate nuclear and cytoplasmic expression of caspase 3 antigen Figure 2 (C, D). Furthermore, agomelatine and vitamin D3-treated group showed mild nuclear and cytoplasmic expression of caspase 3 antigen Figure 2 (E). 


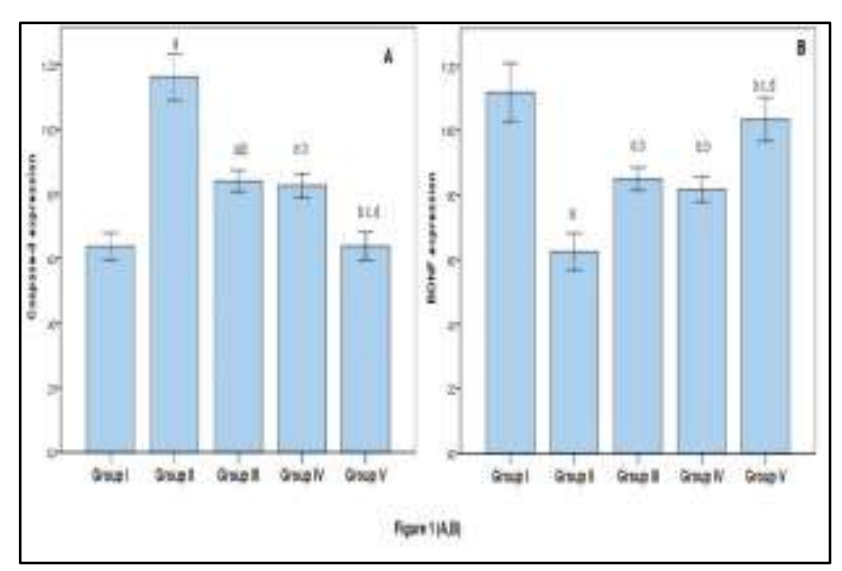

Figure 1: Brain BDNF, and Caspase-3 expressions in different studied groups.

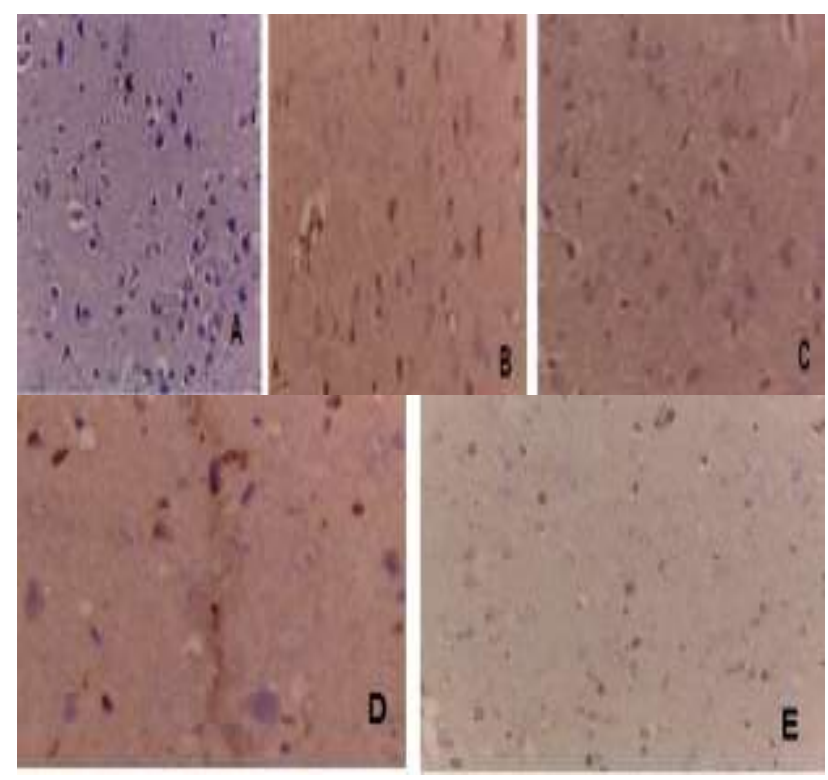

Figure 2: Photomicrographs of rat brain tissues showing different expressions of caspase 3 . in different studied groups.

\section{DISCUSSION}

Depression is considered the highest prevalence psychiatric disorder, with relatively high morbidity, stress is the main risk factor of depression which characterized by physiological changes that occur in response to threatening stimuli. These changes include a cascade of neuroendocrine events mediated by the hypothalamicpituitary-adrenal (HPA) axis. ${ }^{24}$

In the current study, depression was induced experimentally by chronic injection of high corticosterone levels for 21 days. The corticosterone-induced depression model mimics the dysfunction of the HPA (hypothalamuspituitary-adrenal) axis in depression and fulfills adequate face, construct, and predictive validity as an animal model of depression. ${ }^{12}$
The current study has revealed that repeated administration of corticosterone significantly caused behavioral changes in rats in the form of increasing immobility time of tail suspension test (TST) and increasing latency time, decreasing the number of central square crossing, rearing, and line crossing in the open field test. The behavioral changes are accompanied by a significant decrease in brain tissue levels of BDNF, serotonin, and dopamine with a significant increase of TNF- $\alpha$. These results are accompanied by a marked increase in apoptosis in brain tissue as detected by immunohistochemistry.

These results can be explained by many studies showing that repeated exposure to high levels of corticosterone leads to a downregulation of hippocampal glucocorticoid receptors, which impairs the ability of the hippocampus to control glucocorticoid negative feedback, This leads to further hypersecretion of glucocorticoids, and this is thought to produce neuronal changes in several brain regions, including the hippocampus and amygdala ${ }^{25}$ Persistently elevated glucocorticoid levels lead to decreased neurogenesis, and finally apoptosis. ${ }^{4}$ Also, the immune system is activated, and macrophage activity is increased which accounts for the increased production and release of cytokines, such as IL-1 $\beta$, IL-6, and TNF- $\alpha$ which may contribute to the reduction of neurogenesis. ${ }^{26}$ The activation of microglia and the production of proinflammatory cytokines further contributed to dopaminergic and serotonergic neurons and terminals damage. As a consequence of microglial activation, the functions of the other glial cells mainly astrocytes are changed and the production of BDNF is decreased. ${ }^{27}$

BDNF can promote the proliferation and differentiation of multiple types of neurons. BDNF also has a great influence on the plasticity of neurons and the synthesis of neurotransmitters and other neurotrophic factors. ${ }^{28}$ This explains the significant decrease in the brain tissue level of dopamine and serotonin in our study.

In the current study, agomelatine administration resulted in a significant decrease in the immobility time of TST, a decrease of latency time, and an increase in the number of central square crossing, rearing, and line crossing in open field test but not reach the control level.

These results are in accordance with, who stated that administration of agomelatine significantly decreased the duration of immobility time and improve other behavioral parameters in corticosterone-induced depression in rats. ${ }^{29}$ The therapeutic efficacy of agomelatine in depressive disorders is mainly attributed to its action on MT1 and MT2 and 5-HT2C receptors, which are largely present in the frontal cortex, amygdala, hippocampus, cortico-limbic structures and hypothalamus and these structures, are involved in the regulation of mood and cognition. ${ }^{30}$

It is evident that serotonin and dopamine levels in the brain are influential to many behavioral symptoms of 
depression, such as low mood, vigilance, reduced motivation, fatigue, and psychomotor agitation or retardation. ${ }^{31}$ In the current study, regarding brain neurotransmitter tissue levels of dopamine and serotonin, it was found that the agomelatine treated group significantly increased these neurotransmitters when compared with the untreated depressed group. These results are in agreement with, who revealed that agomelatine causes the release of both noradrenaline and dopamine at the fronto-cortical noradrenergic and dopaminergic pathways. ${ }^{32}$

Moreover, the administration of agomelatine caused a significant increase in brain tissue level of BDNF in the agomelatine-treated depression-like behavior group when compared to the untreated depression-like behavior group. This can be explained by Gumuslu and his team, who demonstrated that agomelatine treatment modulates the expression of BDNF through functional interaction between melatonergic MT1/ MT2 and serotonergic 5HT2C receptors, supporting the concept that intracellular events can be regulated via the synergistic activity of different neuromodulator systems. ${ }^{33}$

Another interesting point of view is the anti-inflammatory effect of agomelatine, as our results revealed a decrease in the brain tissue level of TNF- $\alpha$ in the agomelatine treated group when compared to the untreated depression-like behavior group. Agomelatine protection against inflammation appears to be mediated through MT1 and possibly MT2 receptors. Consequently, it resets the disturbed rhythms and sleep-wake rhythms which have been shown to adversely affect inflammation; Moreover, agomelatine as an immunoregulatory agent, acts on the progression of the inflammatory response by causing changes in microglia as well as in systems that may lie downstream cytokine induction. ${ }^{13}$

Interestingly, our results showed that vitamin D3 treated depression-like behavior groups resulted in a significant decrease in immobility time in TST, a significant decrease of latency time, an increasing number of central square crossing, rearing, and line crossing through open field test but not reach the control group results. These behavioral improvements were accompanied by a significant increase in brain tissue levels of BDNF, serotonin, and dopamine with a significant decrease of TNF- $\alpha$. and apoptosis of brain tissues.

These results were in agreement with Hanaa and her team, who stated that the behavioral profile of low immobility and enhanced swimming is correlated with a selectively high serotonergic activity. ${ }^{14,30}$ In addition, the decrease of immobility time maybe also due to the induction of brain dopamine content by vitamin D3 supplementation. As, vitamin D3 may increase the synthesis and/or stimulate the release of neurotransmitters, including serotonin, dopamine, and norepinephrine by Patrick and his team. ${ }^{18,34}$ Additionally Cui and his team, observed that vitamin D3 treatment ameliorates neurobehavioral deficits, caspase 3, and brain edema following traumatic brain injury. ${ }^{35}$ The possible mechanism for the inhibition of TNF- $\alpha$ by vitamin D3 is mediated through the inhibition of NFKB, the major transcription factor for TNF- $\alpha$. in various cell types and affected various inflammatory and immune processes. ${ }^{36}$ Moreover, vitamin D3 was found to be a potent inducer of BDNF expression and it is contributed to the regulation of BDNF in vivo. ${ }^{14}$ While another study concluded that it was premature to report a significant clinical effect of vitamin D supplementation on depression in humans. ${ }^{8}$

Another interesting point of view in the current study is coadministration of agomelatine and vitamin D3 concomitantly with intraperitoneal administration of corticosterone and for 21 days resulted in significant improvement of behavior parameters as well as brain neurotransmitters, TNF- alfa and BDNF compared to corticosterone depressed non treated rats and compared to monotherapy with either each drug alone, these results were confirmed with immune-histochemical, this beneficial neuroprotective effect may be due to synergistic mechanisms which could provide a good combination to ameliorate corticosterone-induced depression.

\section{CONCLUSION}

This study concludes that agomelatine and vitamin D3 have a neuroprotective effect on the progression of corticosterone induced depression-like behavior. Also, our findings recommend the combination of vitamin D and agomelatine as a promising candidate for better therapy against depression.

\section{ACKNOWLEDGEMENTS}

Authors would like to thank Faculty of Medicine, Benha university for great help and valuable constructive cooperation in this work.

\section{Funding: No funding sources}

Conflict of interest: None declared

Ethical approval: The study was approved by the Institutional Ethics Committee of Faculty of medicine, Benha University.

\section{REFERENCES}

1. Aminpoor H, Afshinfar J, Mostafaei A, Ostovar S. Validation of Goldberg's Depression Scale in academic and non-academic peoples. Ann Biological Res. 2012;3(9):4564-73.

2. Aan Het RM, Mathew SJ, Charney DS. Neurobiological mechanisms in major depressive disorder. CMAJ. 2009; 180:305-13.

3. Anacker C, Patricia A, Zunszain LAC, Carmine MP. The glucocorticoid receptor: Pivot of depression and of antidepressant treatment? Psycho-neuroendocrinol. 2011;36(3):415-25. 
4. Jesulola E, Micalos P, Baguley IJ. Understanding the pathophysiology of depression: From monaamines to the neurogenesis hypothesis model-are we there yet? Behavioural brain res. 2018;341:79-90.

5. Boas GRV, De Lacerda RB, Paes MM, Gubert P, Da Cruz Almeida WL, Rescia VC, et al. Molecular Aspects of Depression: A Review from neurobiology to treatment. Eur J pharmacol. 2019;851:99-121.

6. Goodwin GM, Emsley R, Rembry S. Agomelatine Study Group: Agomelatine prevents relapse in patients with major depressive disorder without evidence of a discontinuation syndrome: a 24-week randomized, double-blind, placebo-controlled trial. J Clin Psychiatry. 2009;70:1128-37.

7. Fernandes DA, Eyles D, Féron F. Vitamin D, a neuroimmunomodulator: Implications for neurodegenerative and autoimmune diseases. Psychoneuroendocrinol. 2009;34:S265-77.

8. Eyles, D.W.; Burne, T.H. and McGrath, J.J. Vitamin $\mathrm{D}$, effects on brain development, adult brain function and the links between low levels of vitamin D and neuropsychiatric disease. Front Neuroendocrinol. 2013 Jan; 34(1):47-64.

9. Wang JY, Wu JN, Cherng TL, Hoffer BJ, Chen HH, Borlongan CV et al. Vitamin D3 attenuates 6hydroxydopamine-induced neurotoxicity in rats. Brain Res. 2001;904:67-75.

10. Stio M, Treves C, Martinesi M, Bonanomi AG. Biochemical effects of KH 1060 and anti-TNF monoclonal antibody on human peripheral blood mononuclear cells. Int Immunopharmacol, 2005;5:649-59.

11. Handel AE, Giovannoni G, Ebers GC. Environmental factors and their timing in adult-onset multiple sclerosis. Nat Rev Neurol. 2010;6:156-66.

12. Xie X, Shen Q, Ma L, Chen Y, Zhao B, Fu Z. Chronic corticosterone-induced depression mediates premature aging in rats. $J$ Affect Disord. 2018;229:254-61.

13. Ali AA, Rahman Z, Alwakeel AI, Masoud MA, Elansary AK. Comparative Study on the Activity of Agomelatine and/or Curcumin against Development of Depression in Rats. iMedPub j. 2016;2(4):33.

14. Hanaa HA, Samiha MA, Fatma MA, Heba AM. Significance of vitamin D in combination with calcium in modulation of depression in the experimental model. Der Pharma Chemica, 2015;7(1):128-47.

15. Carrey N, McFadyen MP, Brown RE. Effects of chronic methylphenidate administration on the locomotor and exploratory behavior of prepubertal mice. J Child Adolescent Psychopharmacol. 2000:10:277-86.

16. Brown RE, Corey SC, Moore AK. Differences in measures of exploration and fear in MHC-congenic C57BL/6J and B6-H-2K mice. Behavior Genetics. 1999;26:263-71.

17. Venkatramaniah C, Praba MA, Ganesh K. Protective Role of Acorus Calamus and Beta Asarone In Exploration and Anxiety Levels on Experimental
Epileptic Rat Model. Int J Anat Res. 2017;5(3.1):4067-72.

18. Can A, Dao DT, Terrillion CE, Piantadosi SC, Bhat S, Gould TD. The Tail Suspension Test. J Vis Exp. 2012;59:e3769.

19. Lowry OH, Rosebrough NJ, Farr AL, Randall RJ. Protein measurement with the folin phenol reagent. J Biol Chem. 1951;193:265-75.

20. Ciarlone EA. Determination of catecholamines spectrophoto-flurometrically. Am J Physiol. 1978;125:731-7.

21. Taylor PC. Anti-TNF therapy for rheumatoid arthritis and other inflammatory diseases. Mol Biotechnol. 2001;19(2):153-68.

22. Dekel T, Assaf L, Roman G, Sharon H, Alon C. Resilience to chronic stress is mediated by hippocampal brain-derived neurotrophic factor. J Neurosci. 2011;31(12):4475-83.

23. Livak KJ, Schmittgen TD. Analysis of relative gene expression data using real-time quantitative PCR and the 2- $\Delta \Delta$ CT method. Methods. 2001;25(4):402-8.

24. Yohn CN, Gergues MM, Samuels BA. The role of 5HT receptors in depression. Molecular Brain. 2017;10:28

25. Schmidt MV, Sterlemann V, Wagner K, Niederleitner B, Ganea K, Liebl C et al. Postnatal glucocorticoid excess due to pituitary glucocorticoid receptor deficiency: differential short- and long-term consequences. Endocrinol. 2009;150(6):2709-16.

26. Liu H, Kaur J, Dashtipour K, Kinyamu R, Ribak CE, Friedman LK. Suppression of hippocampal neurogenesis is associated with developmental stage, number of perinatal seizure episodes, and glucocorticosteroid level. Exp Neurol. 2003;184(1):196-213.

27. Dean J, Keshavan M. The neurobiology of depression: an integrated view. Asian J Psychiatr. 2017;27:10111.

28. Pittenger C, Bloch MH. Pharmacological treatment of obsessive-compulsive disorder. Psychiatr Clin North Am. 2014;37:375-91.

29. Rainer Q, Xia L, Guilloux JP, Gabriel C, Mocaë RE, David DJ. Beneficial behavioural and neurogenic effects of agomelatine in a model of depression/anxiety. Int $\mathrm{j}$ neuropsychopharmacol. 2012;321(3):15-35.

30. Srinivasan V, Zakaria R, Othman Z, Lauterbach EC, Acuna-Castroviejo D, AgoSomwaru LL. The natural history of subclinical hypothyroidism in the elderly: the cardiovascular health study. J Clin Endocrinol Metabol. 2012;97:1962-9.

31. Treadway MT. The Neurobiology of Motivational Deficits in Depression--An Update on Candidate Pathomechanisms. Curr Top Behav Neurosci. 2016;27:337-55.

32. De Berardis D, Conti C, Marini S, Ferri F, Iasevoli F, Valchera A, et al. IS there a role for agomelatine in the treatment of anxiety disorders? A review of published data. Int J Immunopathol-Pharmacol. 2013;26(2):299-304. 
33. Gumuslu E, Mutlu O, Sunnetci D, Ulak G, Celikyurt IK, Cine N, et al. The Antidepressant Agomelatine Improves Memory Deterioration and Upregulates CREB and BDNF Gene Expression Levels in Unpredictable Chronic Mild Stress (UCMS)-Exposed Mice. Drug Target Insights. 2014;8:11-21.

34. Patrick RP, Ames BN. Vitamin D hormone regulates serotonin synthesis. Part 1: Relevance for autism. FASEB J. 2014;28:2398-413.

35. Cui C, Song S, Cui J, Feng Y, Gao J, Jiang P. Vitamin D Receptor Activation Influences NADPH Oxidase (NOX2) Activity and Protects against Neurological Deficits and Apoptosis in a Rat Model of Traumatic
Brain Injury. Oxidative Med Cell Longevity. 2017;2017:13.

36. Cohen-Lahav M, Shany S, Tobvin D, Chaimovitz C, Douvdevani A. Vitamin D decreases NFkappaB activity by increasing IkappaBalpha levels. Nephrol Dial Transplant. 2006;21(4):889-97.

Cite this article as: Emam HT, Abu-Raia NH. Vitamin D3 augments the antidepressant effect of agomelatine against repeated corticosterone-induced depressive-like behavior in rats. Int J Basic Clin Pharmacol 2021;10:10-7. 